\title{
High Focused Ultrasound in a Case of Previously Untreated Breast
} Cancer

\author{
Hans-Christian Kolberg, MD, $P h D^{1^{*}}$ and Cornelia Kolberg-Liedtke, MD, PhD ${ }^{2}$ \\ ${ }^{1}$ Marienhospital Bottrop, Bottrop, Germany \\ ${ }^{2}$ Charité - Universitätsmedizin Berlin, Berlin, Germany
}

*Corresponding author: Priv.-Doz. Dr. med Hans-Christian Kolberg, Klinik für Gynäkologie und Geburtshilfe, Marienhospital Bottrop gGmbH, Josef-Albers-Str. 70, 46236 Bottrop, Germany, Tel: +4920411061601, Fax: +4920411061609

\begin{abstract}
Introduction: High focused ultrasound is a non-invasive treatment used for destroying benign and potentially also malignant tumors. Recent data have suggested that the generation of large volumes of tumor debris by high focused ultrasound may initiate an adaptive antitumor immune response by the release of tumor antigens and damage associated molecular patterns

Case: The patient, a 48-year-old woman who was diagnosed with hormone receptor positive HER2 negative breast cancer 17 months before presentation had repeatedly refused any state-of-the-art treatment, instead she specifically asked to be treated with high focused ultrasound. After an intense discussion in our multidisciplinary tumor board we decided to treat her primary tumor with the Echopulse device. 10 months after her treatment, the tumor in the breast showed a complete remission by ultrasound and the involved axillary lymph node showed a more than $50 \%$ reduction in size.

Conclusion: The observed local complete remission in the breast and partial but substantial remission of the involved axillary lymph node may add to the body of evidence indicating a systemic, possibly immunologic, effect of local therapy of a primary tumor with high focused ultrasound. This possible effect needs further investigation in prospective clinical trials.
\end{abstract}

\section{Keywords}

Breast cancer, Focused ultrasound, Local therapy, Echopulse

\section{Introduction}

High focused ultrasound is a non-invasive treatment used for destroying benign and potentially also malignant tumors. An ultrasound beam is focused at the tar- get volume resulting in increased heat at the treated site without destroying adjacent tissue. This principle is illustrated in Figure 1.

The heat at the target site causes coagulative necrosis and protein denaturation [1]. This technique is already used for the treatment of symptomatic breast fibrodenoma in clinical routine and results in a significant shrinkage of fibroadenoma and good symptom control [2]. Treatment is guided by imaging in real time, depending on the device by MRI or ultrasound, providing control of treatment progress and patient movements possible biomarkers such as hyperechoic marks.

Recent data have suggested that the generation of large volumes of tumor debris by high focused ultrasound may initiate an adaptive antitumor immune response by the release of tumor antigens and damage associated molecular patterns [3]. Here we are presenting a case of local and distant response to high focused ultrasound in a case of previously untreated primary breast cancer.

\section{Case}

The patient, at the time of presentation in May 2017 48-years-old, was diagnosed with breast cancer in December 2015. She had no other medical conditions and took no medication. At the time of first diagnosis the ultrasound diameters of the tumor in her left breast were $2.0 \mathrm{~cm} \times 1.5 \mathrm{~cm} \times 1.9 \mathrm{~cm}$. No suspect axillary lymph nodes were detectable. Diagnosis was verified by core cut biopsy. Initial tumor stage was

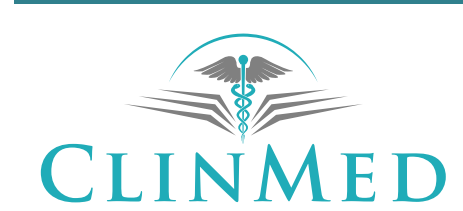

INTERNATIONAL LIBRARY

Citation: Kolberg HC, Kolberg-Liedtke C (2019) High Focused Ultrasound in a Case of Previously Untreated Breast Cancer. Clin Med Rev Case Rep 6:256. doi.org/10.23937/2378-3656/1410256

Accepted: February 18, 2019: Published: February 20, 2019

Copyright: (c) 2019 Kolberg HC, et al. This is an open-access article distributed under the terms of the Creative Commons Attribution License, which permits unrestricted use, distribution, and reproduction in any medium, provided the original author and source are credited. 


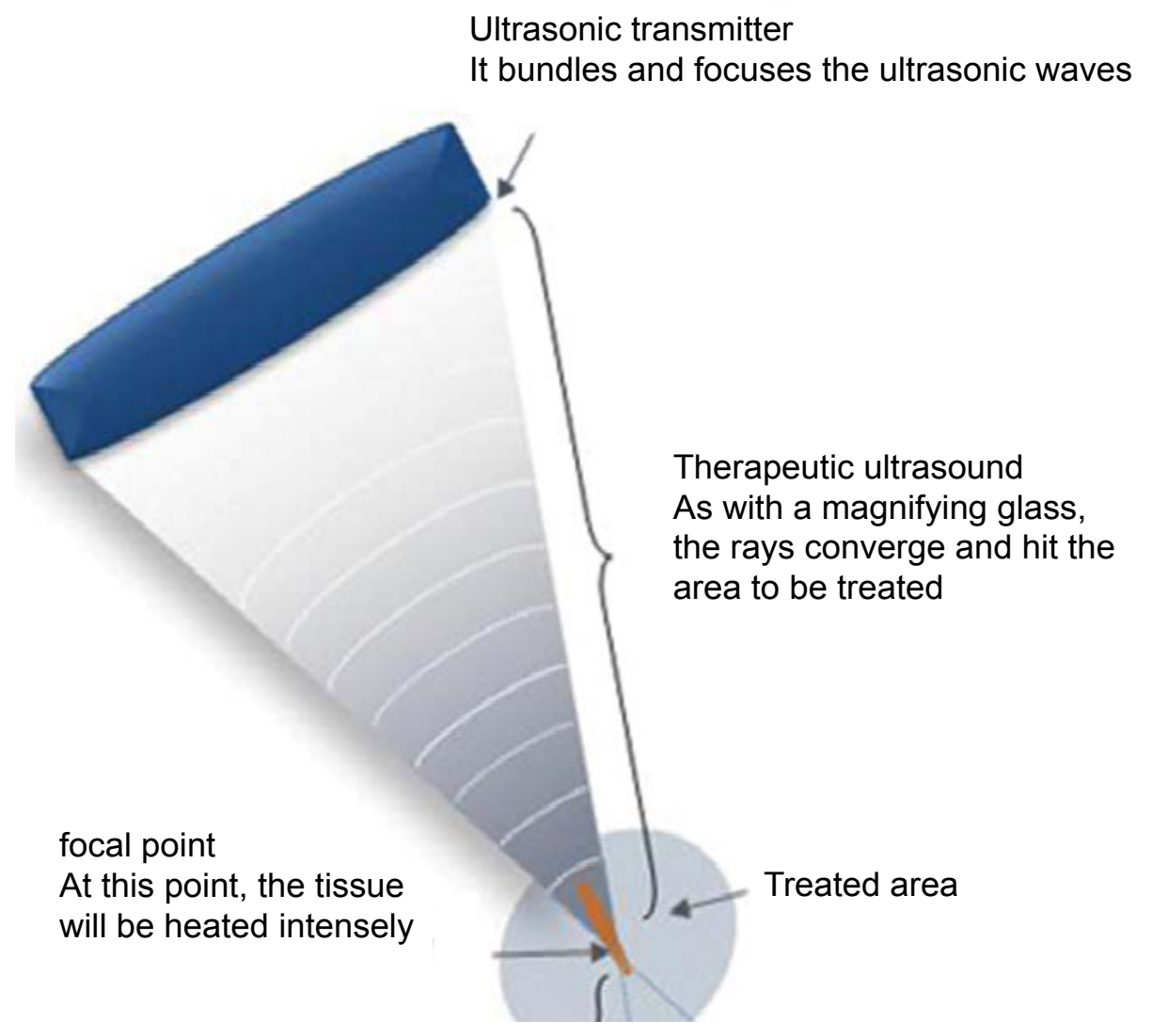

Figure 1: The principle of focused ultrasound (source: www.theraclion.com).

reported as cT2 cNO Mx G2, estrogen receptor positive, progesterone receptor positive, HER2neu negative. The patient refused staging and also repeatedly refused any recommendations regarding surgery, radiation and systemic therapy. In May 2017, 17 months after first diagnosis, she was first seen in our center. She had no symptoms of distant disease, her tumor measured $3.41 \mathrm{~cm} \times 3.58 \mathrm{~cm} \times 2.43 \mathrm{~cm}$. In her left axilla a lymph node was palpable measuring $2.34 \mathrm{~cm} \times 1.77 \mathrm{~cm} \times 1.0$ $\mathrm{cm}$ by ultrasound and showing all signs of malignancy. We urgently recommended her to accept state-of-theart therapy for her breast cancer and went through all the options with her again. After intense counseling she repeatedly refused surgery, radiation and/or any kind of systemic therapy again and specifically asked for treatment with highly-focused ultrasound. We repeatedly stated that high focused ultrasound in breast cancer was still highly experimental, that no estimates about a possible success could be given and that high focused ultrasound was no suitable alternative to stateof-the-art therapy. The patient insisted and we after discussion in our multidisciplinary tumor board and also in our multidisciplinary board on focused ultrasound agreed to treat her in an individual concept without any estimates about a possible treatment effect whatsoever.

After obtaining informed consent of the patient for this individual approach we treated her breast tumor with high focused ultrasound using the Echopulse device (Theraclion, Malakoff, France) that has received a CEmark for the treatment of breast and thyroid nodules.

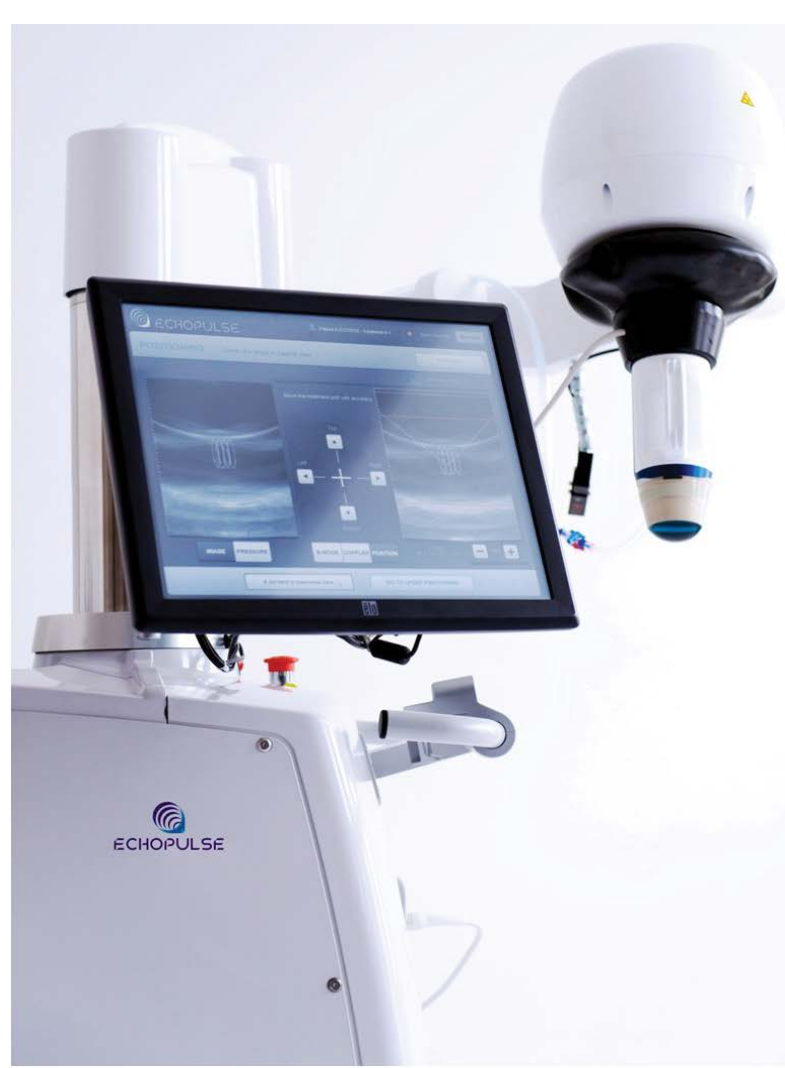

Figure 2: The Echopulse device (source: www.theraclion. com).

The device is depicted in Figure 2.

In clinical routine the only breast tumors treated with the Echopulse are fibroadenomas. The visualization and 


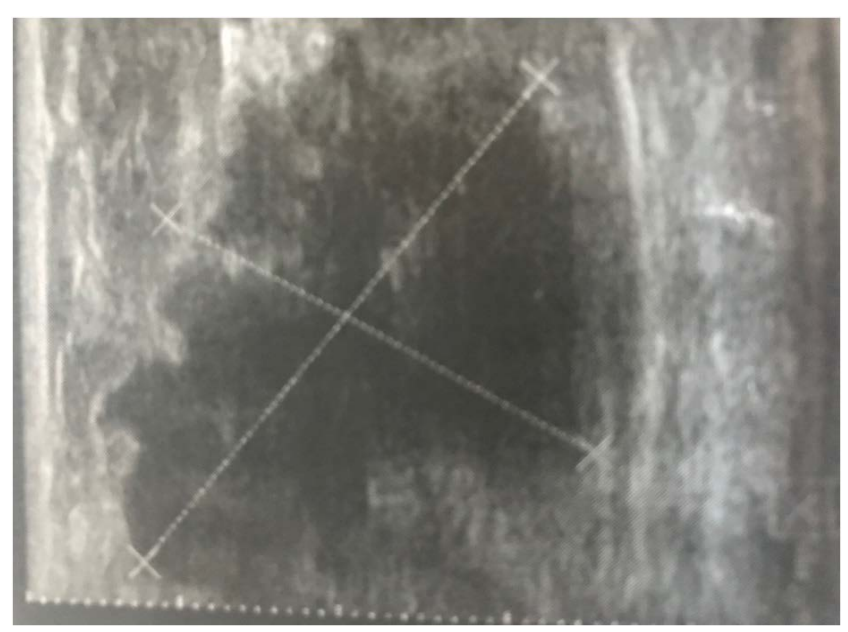

Figure 3: Breast tumor before echotherapy.

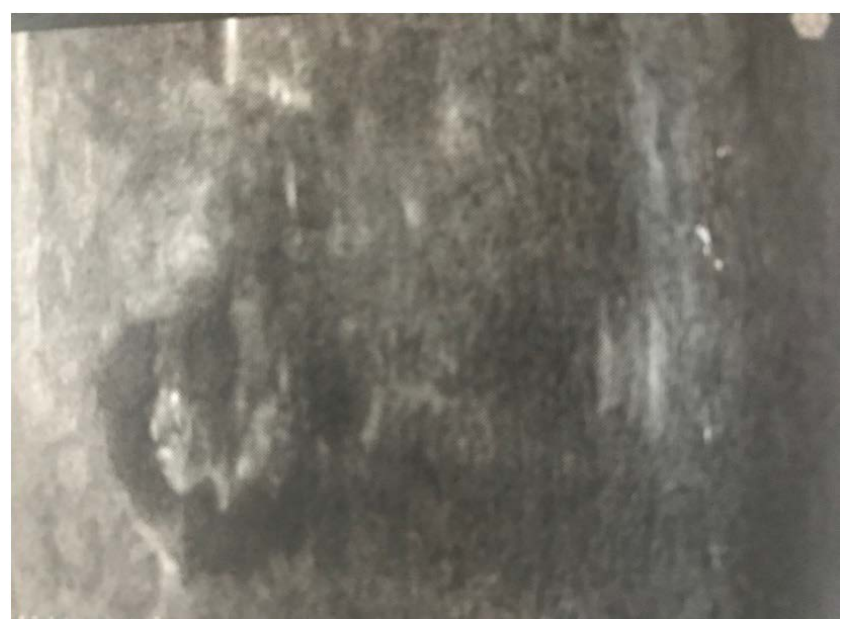

Figure 4: Breast tumor immediately after echotherapy with hyperechoic marks.

treatment unit (VTU) of the device includes a 7.5-12 $\mathrm{MHz}$ diagnostic transducer and a $3.0 \mathrm{MHz}$ therapeutic imaging transducer. The VTU of the Echopulse performs tissue imaging, power delivery, measurements of the temperature of the cooling liquid and the applied pressure. The skin is cooled to $12-14{ }^{\circ} \mathrm{C}$ during the course of the treatment to prevent heat-associated side effects. Temperatures in the target region are reaching $80^{\circ} \mathrm{C}$ during treatment. The treatment was performed in local anesthesia. During echotherapy the tumor showed hyperechoic marks that in breast fibroadenomas are associated with successful treatment. Pre- and posttreatment images are shown in Figure 3 and Figure 4.

After performing high focused ultrasound we again urgently recommended her to accept and undergo regular treatment for her breast cancer. The patient again refused, but showed up for a follow-up in October 2017,5 months post echotherapy. She had no symptoms of distant disease, her breast cancer measured $2.78 \mathrm{~cm} \times$ $2.99 \mathrm{~cm} \times 1.99 \mathrm{~cm}$ by ultrasound, a reduction in volume by $44.5 \%$. The lymph node in her left axilla measured $2.77 \mathrm{~cm} \times 2.77 \mathrm{~cm} \times 1.19 \mathrm{~cm}$, a progression compared to the measurement 5 months before. As before the patient refused any state of the art therapy. The next follow up in March 2018 showed a complete remission of the breast tumor in ultrasound and a remission of her axillary lymph node to $0.9 \mathrm{~cm}$. She refused staging but showed no symptoms of distant disease.

\section{Conclusion}

Successful treatments of breast cancer cases with ultrasound guided high focused ultrasound resulting in complete destruction of the tumors and a favorable local control have been reported [4,5]. "Treat and resect" studies demonstrated that high focused ultrasound does not only result in a favorable local control but also in a significant tumor necrosis [6]. Furthermore, it has been discussed that tumor debris resulting from high focused ultrasound may generate the release of tumor antigens stimulating the immune system [7]. Theoretically this stimulation of an immune answer could result in the creation of an in-situ cancer vaccine with an impact on tumor sites distant from the treated target site such as regional lymph nodes or metastatic disease in analogy to the abscopal effect seen after local radiotherapy with high doses [3]. This effect is not exclusive for focused ultrasound, other thermal approaches of killing cancer cells have also been successful [8]. Of course the possibilities of high focused ultrasound are exceeding the observations in this case by far. It has been demonstrated that high focused ultrasound can release drugs encapsulated in microchambers, a concept that could in the future dramatically reduce the side effects of chemotherapy [9].

With the case presented here we did not only see a local complete remission in the breast detected by ultrasound but also a partial but substantial remission of the involved axillary lymph node. Although we are extremely cautious regarding the interpretation of a single case, the shrinkage of a regional lymph node as an untreated site may add to the body of evidence indicating a systemic, possibly immunologic, effect of local therapy of a primary tumor with high focused ultrasound. Our observation could be explainable by the possible effects of tumor ablation: (1) Destruction of tumor mass (2) The release of tumor antigens, making them available for uptake by antigen-presenting cells, (3) The release of damage-associated molecular patterns and (4) Creation of an in situ antigen depot containing all types of tumor proteins already described $[3,10,11]$.

This possible effect needs further investigation in prospective clinical trials, optimally in combination with immune therapies such as checkpoint inhibitors.

\section{Statement}

HCK and CKL contributed equally to the submitted work.

\section{Acknowledgements}

The authors confirm that there has been no outside funding for the submitted work. 


\section{Conflicts of Interest}

HCK received honoraria from Theraclion and holds stock of Theraclion. CKL has nothing to report.

\section{References}

1. Peek MCL, Wu F (2018) High-intensity focused ultrasound in the treatment of breast tumours. Ecancermedicalscience 12: 794.

2. Peek MCL, Ahmed M, Scudder J, Baker R, Charalampoudis, et al. (2018) High-intensity focused ultrasound in the treatment of breast fibroadenomata (HIFU-F trial). Int $\mathrm{J}$ Hyperthermia 34: 1002-1009.

3. van den Bijgaart RJ, Eikelenboom DC, Hoogenboom M, Fütterer JJ, den Brok MH, et al. (2017) Thermal and mechanical high-intensity focused ultrasound: Perspectives on tumor ablation, immune effects and combination strategies. Cancer Immunol Immunother 66: 247-258.

4. Peek MC, Ahmed M, Napoli A, ten Haken B, McWilliams S, et al. (2015) Systematic review of high-intensity focused ultrasound ablation in the treatment of breast cancer. $\mathrm{Br} \mathrm{J}$ Surg 102: 873-882.

5. Peek MCL, Douek M (2017) Ablative techniques for the treatment of benign and malignant breast tumours. $J$ Ther Ultrasound 5: 18.
6. Merckel LG, Knuttel FM, Deckers R, van Dalen T, Schubert G, et al. (2016) First clinical experience with a dedicated MRI-guided high-intensity focused ultrasound system for breast cancer ablation. Eur Radiol 26: 4037-4046.

7. den Brok MH, Sutmuller RP, van der Voort R, Bennink EJ, Figdor CG, et al. (2004) In situ tumor ablation creates an antigen source for the generation of antitumor immunity. Cancer Res 64: 4024-4029.

8. He W, Frueh J, Wu Z, He Q (2016) Leucocyte MembraneCoated Janus Microcapsules for Enhanced Photothermal Cancer Treatment. Langmuir 32: 3637-3644.

9. Gai M, Frueh J, Tao T, Petrov AV, Petrov VV, et al. (2017) Polylactic acid nano- and microchamber arrays for encapsulation of small hydrophilic molecules featuring drug release via high intensity focused ultrasound. Nanoscale 9: 7063-7070.

10. Xu ZL, Zhu XQ, Lu P, Zhou Q, Zhang J, et al. (2009) Activation of tumor-infiltrating antigen presenting cells by high intensity focused ultrasound ablation of human breast cancer. Ultrasound Med Biol 35: 50-57.

11. Zhou Q, Zhu XQ, Zhang J, Xu ZL, Lu P, et al. (2008) Changes in circulating immunosuppressive cytokine levels of cancer patients after high intensity focused ultrasound treatment. Ultrasound Med Biol 34: 81-87. 